\title{
ARTIGO
}

dO https://doi.org/ 10.22481/praxisedu.v15i34.5508

\section{IOGA NA ESCOLA: POSSIBILIDADES E DESAFIOS}

\author{
YOGA AT SCHOOL: POSSIBILITIES AND CHALLENGES
}

\author{
YOGA EN LA ESCUELA: POSIBILIDADES Y DESAFÍOS
}

\author{
Fernanda Pastori Franzé \\ Universidade Estadual Paulista - Brasil \\ Fernanda Rossi \\ Universidade Estadual Paulista - Brasil
}

\begin{abstract}
Resumo: O objetivo da pesquisa é analisar o desenvolvimento e os fatores que impactam o ensino da ioga na educação infantil e nos anos iniciais do ensino fundamental, de acordo com professoras participantes de um programa de formação continuada em ioga e educação. A pesquisa qualitativa foi desenvolvida no decorrer de um programa de formação continuada em ioga, com 23 professoras da educação básica do Sistema Municipal de Ensino de Bauru-SP. Os dados foram coletados por questionário, no qual as professoras indicaram a frequência de desenvolvimento da ioga com suas turmas e os desafios para iniciar ou dar continuidade ao trabalho didático-pedagógico com a ioga na escola. Os resultados indicaram que a maioria das participantes desenvolve a ioga com suas turmas semanalmente. E para a continuidade do ensino da ioga na educação infantil e nos anos iniciais do ensino fundamental foram relatadas: a necessidade de aprofundamento teórico-prático; o domínio didático-pedagógico; estrutura e materiais adequados para o desenvolvimento das aulas; a necessidade do envolvimento da equipe escolar; realização de planejamento ou o preparo prévio das aulas; desenvolvimento de trabalho contínuo com a turma e, por último, a presença da ioga como conteúdo programático nos currículos escolares. Conclui-se que a formação proporcionou às professoras conhecimentos da ioga, possibilitando sua ressignificação para o contexto escolar, bem como o reconhecimento da necessidade constante de estudos, pesquisas e práticas sobre a ioga para sua continuidade, ampliação e reconhecimento como conteúdo na escola.
\end{abstract}

Palavras-chave: Ioga. Educação básica. Formação continuada de professores.

\begin{abstract}
The aim of the research is to analyze the development and factors that impact the teaching of yoga in early childhood education and in the early years of elementary education, according to teachers participating in a continuing education program in yoga and education. Qualitative research was developed during a continuing education program in yoga, with 23 teachers of basic education in the Bauru-SP Municipal Teaching System. The data were collected through a questionnaire, in which the teachers indicated the frequency of development of yoga with their classes and the challenges to initiate or continue the didactic-pedagogical work with yoga at school. The results indicated that most participants develop yoga with their classes weekly. And for the continuity of the teaching of yoga in early childhood education and in the initial years of elementary education have been reported: the need for theoretical-practical deepening; the didactic-pedagogical domain; lack of structure and physical materials for class development; the need for school staff involvement; conducting planning or prepreparing classes; development of continuous work with the class and, finally, the presence of yoga as
\end{abstract}


a programmatic content in school curricula. It is concluded that the training provided the teachers with a knowledge of yoga, allowing their re-signification to the school context, as well as the recognition of the constant need for studies, research and practices on yoga for its continuity, amplification and recognition as content in the school.

Keywords: Yoga. Basic education. Continuing teaching training.

Resumen: El objetivo de la investigación es analizar el desarrollo y los factores que impactan la enseñanza del yoga en la educación infantil y en los años iniciales de la enseñanza fundamental, de acuerdo con profesoras participantes de un programa de formación continuada en yoga y educación. La investigación cualitativa fue desarrollada en el curso de un programa de formación continuada en yoga, con 23 profesoras de la educación básica del Sistema Municipal de Enseñanza de Bauru-SP. Los datos fueron recolectados por cuestionario, en el cual las profesoras indicaron la frecuencia de desarrollo del yoga con sus clases y los desafíos para iniciar o dar continuidad al trabajo didácticopedagógico con el yoga en la escuela. Los resultados indicaron que la mayoría de las participantes desarrollan el yoga con sus grupos semanalmente. Y para la continuidad de la enseñanza de la yoga en la educación infantil y en los años iniciales de la enseñanza fundamental fueron relatadas: la necesidad de profundización teórico-práctica; el dominio didáctico-pedagógico; la falta de estructura y materiales físicos para el desarrollo de las clases; la necesidad de la participación del equipo escolar; la realización de planificación o la preparación previa de las clases; desarrollo de trabajo continuo con la clase y, por último, la presencia del yoga como contenido programático en los currículos escolares. Se concluye que la formación proporcionó a las profesoras conocimientos del yoga, posibilitando su resignificación para el contexto escolar, así como el reconocimiento de la necesidad constante de estudios, investigaciones y prácticas sobre el yoga para su continuidad, ampliación y reconocimiento como contenido en la escuela.

Palabras clave: Yoga. Educación básica. Formación continuada de profesores.

\section{Introdução}

A linguagem corporal é uma das principais manifestações da criança (AYOUB, 2001; KISHIMOTO, 2001; SAYÃO, 2002), sendo a escola um dos principais espaços institucionais responsáveis pela apropriação desta linguagem, pautando-se em uma educação que valorize as diferentes linguagens humanas. A professora da educação infantil e do ensino fundamental pode propiciar a vivência autêntica das manifestações corporais na escola, contribuindo para que as crianças elaborem os seus próprios significados relacionados à cultura corporal de movimento.

A linguagem corporal que a criança expressa é intencional e traz significados, sentidos e representações (EHRENBERG, 2014), sendo prerrogativa dos professores garantir o acesso à riqueza de temas e conteúdos necessários para uma formação humana fundamentada em princípios de autonomia e cidadania (DEBORTOLI, 2002), além de propiciar às crianças a 
apropriação, a ampliação e leituras críticas acerca da linguagem do corpo (EHRENBERG, 2014).

Uma das manifestações corporais presentes na sociedade contemporânea é a ioga, filosofia e prática corporal que apresenta potencial para ampliar as possibilidades de linguagem corporal. A palavra ioga significa união e seus pressupostos contribuem para a formação integral do ser humano, o que implica considerar o corpo como um todo. A prática da ioga no ambiente escolar, sobretudo na educação infantil, ainda é pouco conhecida, porém estudos indicam benefícios para a formação social, afetiva e física das crianças (FARIA et al., 2014; SILVEIRA, 2012; MARTINS; CUNHA, 2011).

Nesse esteio, as práticas de ioga tem sido cada vez mais difundidas no meio educacional. O desenvolvimento dos ásanas (posturas físicas), yamas e nyamas (valores), pranayamas (respiração) e técnicas de concentração e relaxamento podem ser articulados com diferentes momentos e espaços da rotina escolar, sendo que o processo de reconhecimento do corpo na ioga ocorre de forma integral, abordando o corpo humano por inteiro, defendendo a harmonia e o equilíbrio de seu funcionamento. Flak e Coulon (2008) ressaltam a importância de a criança tomar consciência desse conceito de integralidade e que os exercícios da ioga podem despertar a consiciência de si e de atenção ao outro. Para Iyengar (2014), as práticas pedagógicas da ioga envolvem aspectos físicos, emocionais e sociais, por isso quando se propõe desenvolver a ioga com as crianças a integralidade do corpo será sentida por meio do desenvolvimento de alguns dos oito passos da ioga de Patañjali, filósofo indiano pioneiro em organizar e sistematizar a ioga.

Pensar nas possibilidades de inserção desta manifestação corporal no contexto escolar remete-nos a refletir sobre a apropriação da filosofia e prática da ioga por professores, de modo que possam ressignificar tais conhecimentos em processos de ensino e aprendizagem com as crianças, sendo que um dos caminhos para tal empreendimento é via ações de formação continuada.

A formação continuada de professores é um tema recorrente nas discussões sobre políticas educacionais e qualidade de ensino. O objetivo desta formação não é suprir déficits da formação inicial, mas possibilitar ao professor produzir instrumentos intelectuais que julgue necessários para a qualidade de suas aulas, atendendo às suas necessidades (SACRISTÁN, 1999; FALSARELLA 2004; IMBERNÓN, 2009). É preciso apontar também que a preocupação com a formação continuada deve estar além do domínio de novos conteúdos ou especificações didáticas. Imbernón (2009, p. 47) defende que a formação 
continuada deve ser organizada de forma crítica, revendo bases ideológicas e atitudinais, estendendo-se para o "terreno das capacidades, habilidades, emoções e atitudes", abandonando conceitos de mera atualização didática. Assim, a contribuição das ações de formação continuada deve ser formar um professor crítico, capaz de processar informações, realizar análises, construir conhecimentos, tomar decisões e reformular aquilo que julgar necessário diante do seu cenário de atuação.

Ainda são incipientes as pesquisas que investigam a formação do professor para o desenvolvimento didático-pedagógico com a ioga na escola. Pesquisas como a de Deutsh et al. (2015) e FARIA et al. (2014) abordam experiências das práticas de ioga nas escolas e afirmam seus benefícios tanto para alunos, quanto para professores, emergindo como possibilidade de investigação a formação dos professores para apropriação dos conhecimentos filosóficos e práticos da ioga, de modo a promover sua ressignificação para o contexto escolar.

Nesse sentido, o objetivo desta pesquisa consistiu em analisar o desenvolvimento e os fatores que impactam o ensino da ioga na educação infantil e nos anos iniciais do ensino fundamental, de acordo com professoras participantes de um programa de formação continuada em ioga e educação.

A pesquisa apresentada foi realizada em um programa de formação continuada desenvolvido pela UNESP - Universidade Estadual Paulista ${ }^{1}$ para professores do Sistema Municipal de Ensino de Bauru, das áreas da Pedagogia e Arte.

No referido programa de formação, lócus desta pesquisa, optou-se por uma concepção de formação continuada em que as professoras vivenciassem a ioga, construindo suas experiências pessoais, articuladamente ao desenvolvimento de conhecimentos teóricopráticos, de modo a se tornarem protagonistas na construção de práticas pedagógicas para a inserção da ioga em seus contextos escolares.

\section{A linguagem corporal, a ioga na infância e a formação de professores}

Ao ingressar na escola a criança traz consigo suas primeiras construções sociais até então realizadas com as vivências familiares e em sua comunidade. A cultura que a criança traz consigo é também considerada no processo de apropriação do brincar na educação infantil. Garanhani e Nadolny (2015) apontam que o brincar é um princípio pedagógico que

\footnotetext{
${ }^{1}$ UNESP campus de Bauru, Faculdade de Ciências, Departamento de Educação.
} 
possibilita à criança a ação e a construção de significados perante à realidade. Ainda, para as autoras, o movimento corporal permite à criança deslocar-se, percebendo assim a mobilidade de corpo e o seu entorno, o que ocorre frequentemente nas brincadeiras infantis.

Kishimoto (2010) revela que o brincar é a atividade de maior tempo no cotidiano infantil e deve-se propor às crianças diferentes experiências com o corpo, com os sentidos e com os movimentos. Para tanto, faz-se necessário apresentar à criança diferentes formas de brincadeiras, situando seu corpo nesse momento lúdico, promovendo as sensações que ampliarão a consciência corporal e, cada vez mais, a oportunidade de se expressar, aprender e desenvolver, criando sentido ao que realiza. Garanhani e Nadolny (2015) também afirmam que é dever da escola de educação infantil favorecer o conhecimento, a apropriação e a apreciação da linguagem corporal.

O brincar está pautado na Base Nacional Comum Curricular/BNCC (BRASIL, 2017) como direito de aprendizagem e desenvolvimento das crianças. $\mathrm{O}$ documento relaciona $\mathrm{o}$ ato de brincar com as experiências que devem ser proporcionadas às crianças por meio do corpo e suas emoções, percepções, sensações e expressões, além de considerar o brincar como constituinte do desenvolvimento cognitivo e social. Corroboram Oliveira e Souza (2018) que as brincadeiras na infância promovem o exercício das relações socioculturais, confirmando, assim, a relação da experiência do brincar com a compreensão da realidade e o processo da construção da autonomia.

A expressão por meio da linguagem corporal é para a criança uma das formas de desenvolver a ludicidade, por isso, o movimento do corpo traz à criança a sensação de prazer quando imerso no lúdico. Neira e Macedo (2017) apontam que por meio desta linguagem a criança participa do mundo, constituindo e construindo, também, uma cultura própria da infância. Os autores ressaltam que as crianças devem ter acesso ao patrimônio cultural corporal experimentando as diversas formas em que é apresentado, o que corrobora o argumento de desenvolvimento da ioga com as crianças no contexto escolar, permitindo o conhecimento e a vivência dessa prática milenar iniciada no Oriente. Ainda, conforme Neira e Macedo (2017), apresentar às crianças a cultura corporal produzida pelas diferentes sociedades é proporcionar diferentes olhares, oferecendo novas possibilidades de compreensão, de contemplação, não passiva, mas possibilitando a apropriação conjuntamente com a ressignificação das mais diversas práticas corporais.

A presença da ioga na educação far-se-á dessa forma, incluindo o movimento com sentido, participando deste momento a imaginação e a corporeidade de cada criança. 
Kishimoto (2010) enfatiza que é preciso conciliar a educação com a brincadeira; o ambiente escolar deve estar voltado às possibilidades de brincadeiras nos mais diversos momentos. Segundo Flak e Coulon (2007) as crianças precisam canalizar suas energias de forma harmônica, promovendo a conexão interior em prevalência sobre a conexão com os circuitos externos. Para os autores, a ioga é uma forma de possibilitar às crianças a educação dos sentidos, utilizando-os conscientemente, alertando assim para uma exploração exagerada e prejudicial de todos os sentidos do corpo ao mesmo tempo (como promovem, muitas vezes, os aparelhos eletrônicos).

Martines (2009) relata que a infância é uma fase propícia às práticas de ioga, pois a flexibilidade corporal colabora para o desenvolvimento das posturas, conhecidas como ásanas. A autora também afirma que a prática da ioga não considera apenas as melhorias físicas das crianças, mas a integralidade do corpo, considerando o controle da calma, da concentração e da melhora da respiração. Silveira (2012) e Benvindo (2015) reiteram a visão da ioga sobre a integralidade e equilíbrio do corpo, possibilitando o desenvolvimento das funções cognitivas, afetivas e psicológicas. Essa interpretação integral do corpo é exemplificada quando busca-se regular a respiração conciliando-a com os movimentos. Possignolo (2012) relaciona as práticas de ioga com a melhoria sobre as tensões pelas quais as crianças passam em seu cotidiano, considerando a rotina estressante e conturbada de muitas delas e que pode resultar em agressividade. Para a autora, a ioga pode auxiliar as crianças a desenvolver a consciência de coletividade, compreendendo a importância de um ambiente harmônico e buscando o bem-estar de todos.

Ao desenvolver a ioga como prática pedagógica na escola, consideram-se alguns dos estágios ou passos de acordo com a compilação do Yoga Sutra realizada pelo filósofo indiano Patañjali, por volta de 200 d.C.; texto considerado fundamental para o sistema filosófico da ioga, que indica os oito passos do caminho da ioga, sendo eles: yama, nyama, ásana, pranayama, pratyahara, dharana, dhyana, samadhi (FEUERSTEIN, 1998).

Os yamas (disciplina externa) e nyamas (disciplina interna) se referem a princípios morais e éticos, recomendando a não-violência, a verdade, o desapego, o autoestudo, a disciplina, o contentamento, entre outros; os ásanas são as posturas psicofísicas; os pranayamas são técnicas de controle da respiração; pratyahara é a abstenção dos sentidos; dharana refere-se à concentração; dhyana é definida como meditação e o oitavo e último passo, samadhi, como integração (MASSOLA, 2008). 
Assim, a ioga propicia a reflexão em torno de princípios morais e éticos, o desenvolvimento de posturas para o equilíbrio psicofísico e os exercícios de respiração para a expansão da energia vital. As técnicas de concentração e relaxamento também são desenvolvidas na escola, principalmente por proporcionar aos alunos momentos de contemplação de seus próprios corpos e tranquilidade. Os dois últimos passos (dhyana e samadhi) referem-se, sobretudo, ao mundo adulto, não sendo contemplados nos projetos de ensino para crianças.

O crescente interesse pela prática da ioga pelas crianças, no contexto escolar, pode ser justificado pela visão que esta prática e filosofia apresentam do ser humano: integração entre mente e corpo. É possível, assim, propor às crianças a ampliação do conhecimento sobre seus próprios corpos, rompendo com a visão dicotômica e estigmatizada com que o corpo é concebido na sociedade e na própria educação. A ioga na escola, desenvolvida como prática pedagógica, pode ser trabalhada com objetivos que envolvem os conteúdos da Educação Física e sua finalidade de integrar as crianças no âmbito da cultura corporal; por meio de brincadeiras ou em diferentes momentos do cotidiano escolar, proporcionando às crianças relaxamento, concentração e conhecimento de si.

Benvindo (2015) reforça a ideia de que a ioga na escola é desenvolvida de forma lúdica, considerando o papel da criança como ser social, direcionando a educação para as esferas de realização pessoal e reconhecendo a criança como ser participante da sociedade. Foletto (2016) completa este pensamento ao apontar que as crianças atribuem à ioga a sensação de paz e bem-estar. Ainda, a ioga na escola representa uma possibilidade de ampliação qualitativa em relação à diversificação das manifestações corporais na formação da criança.

Por se tratar de uma prática e filosofia que envolve a integridade do corpo e que necessita de um trabalho unificado, é relevante abordar a formação do professor em relação aos conhecimentos de ioga. Além do domínio dos seus conteúdos para promover o ensino e aprendizagem, cabe refletir, conforme Possignolo (2012), que o professor pode concentrar-se, segundo os ensinamentos da ioga, na busca por um ambiente harmônico, na confiança em si e nos outros, na boa relação com o corpo e seus limites. Pode-se, assim, conciliar esta ideia da ioga com modelos de formação continuada que valorizem e considerem a formação pessoal valorativa do professor. Caetano (2011) ressalta que a dimensão pessoal do professor é uma das ativações mais usadas no processo de ensino e no relacionamento com os alunos, diminuindo a distância entre as partes em função dos diferentes níveis de conhecimentos. A 
autora coloca que quando há capacidade de controlar, entender, avaliar e utilizar as emoções conscientemente, pode haver a potencialização de processos cognitivos, gerando escolhas mais livres, responsáveis e solidárias.

Quando se trata da formação que envolve a linguagem do movimento, as vivências por parte dos professores, nos contextos formativos, tornam-se imprescindíveis, pois seria limitante ensinar uma linguagem sem nunca sequer tê-la vivenciado. Garanhani e Nadolny (2015) relatam em sua pesquisa que a articulação entre a teoria utilizada para embasar os conhecimentos sobre o movimento na educação só alcançam bons resultados se for oportunizado ao professor a prática, cerceada por ações e experiências, gerando reflexões sobre o significado pedagógico que é construído pelo professor.

Strazzacappa (2001) afirma que é preciso que os professores conheçam e descubram seus próprios corpos, considerando que o corpo em sua totalidade está presente no processo educacional e que o professor é uma referência aos seus alunos. Sobre o processo contínuo de formação do professor, Imbernón (2016) aborda a necessidade de reflexão sobre as formações oferecidas, a fim de que habilidades interpessoais e comunicativas sejam constituintes das propostas formativas. Tem-se, neste caso, um apontamento que supera as necessidades metodológicas ou de conteúdo no âmbito da formação de professores.

Portanto, refletir sobre a inserção da ioga na escola remete, também, pensar a formação do professor, de modo a considerar a apropriação dos conhecimentos filosóficos e práticos da ioga tanto para sua formação pessoal, quanto para o desenvolvimento profissional, ressignificando-os para o contexto escolar.

\section{Metodologia}

Este estudo fundamentou-se na abordagem qualitativa de pesquisa. Segundo Bogdan e Biklen (1994), mesmo que o investigador em uma pesquisa qualitativa opte por selecionar questões específicas conforme recolhe os dados, o objetivo desta não é testar hipóteses, mas compreender os comportamentos dos sujeitos participantes da investigação. Minayo (1993) reitera que o uso da pesquisa qualitativa tem como objeto de pesquisa a análise das relações humanas, das representações e intencionalidades e não deve ser reduzida a números ou quantidades.

A pesquisa de campo foi realizada no âmbito de um programa de formação continuada desenvolvido por uma Universidade pública: UNESP - Universidade Estadual Paulista, em 
parceria com o Sistema Municipal de Ensino de Bauru. O programa foi desenvolvido ao longo de um ano e meio e composto por três módulos, com carga horária total de 120 horas.

As participantes do estudo foram 23 professoras, com formação prevalecente em Pedagogia, contando, ainda, com professoras de Arte, atuantes na educação infantil e nos anos iniciais do ensino fundamental. Os dados foram coletados por meio de questionário, contendo uma questão fechada, referente ao número de dias em que a ioga era desenvolvida com alunos; e outra aberta, sobre os desafios para iniciar ou dar continuidade ao trabalho com ioga na escola. O questionário foi aplicado ao final da formação, ou seja, após a realização dos três módulos e respondido por escrito. Gil (2006) aponta o questionário como técnica que permite o conhecimento de opiniões, situações vivenciadas e interesses, sendo vantajoso pela não influência de opiniões por diferentes fatores, além da conveniência para os participantes em relação ao tempo e local em que irão responder.

As professoras participantes da pesquisa assinaram termo de consentimento livre e esclarecido autorizando a publicação das informações, bem como o conhecimento de que seus nomes seriam mantidos em sigilo durante toda a investigação e publicação dos resultados.

O programa assumiu como objetivo geral promover ações de formação continuada no campo da ioga e da educação, visando a (re)construção da corporeidade de professoras e, concomitantemente, a apropriação dos conhecimentos teórico-práticos da ioga para o planejamento didático-pedagógico do conteúdo e inserção na educação infantil e nos anos iniciais do ensino fundamental. As estratégias formativas consistiram em encontros semanais com a vivência de práticas do estilo Hatha Yoga, técnicas de respiração, relaxamento e automassagem, estudos teóricos sobre o corpo/corporeidade, o movimento e a criança, e a produção de material didático-pedagógico para a inserção da ioga com as crianças no contexto escolar.

As vivências dos ásanas da ioga foi o ponto inicial para o desenvolvimento do programa de formação. Nos encontros, as professoras podiam realizar as posturas, conjuntamente com as técnicas de respiração e relaxamento, além de refletir sobre os yamas e nyamas, associados aos valores e atitudes na filosofia da ioga. Como estímulo ao compartilhamento de experiências e a produção coletiva de conhecimentos e práticas, as professoras planejavam aulas para as crianças com seus pares e em conjunto com os agentes formadores. Na sequência, desenvolviam as atividades com suas turmas e registravam por escrito os relatos de experiências e as adaptações necessárias de acordo com a faixa etária e características do grupo. Nos encontros de formação eram compartilhadas as experiências 
entre todas as docentes, destacando possibilidades e desafios para o trabalho didáticopedagógico com a ioga com as crianças, no ambiente escolar.

Por se tratar de uma pesquisa de cunho qualitativo fez-se necessário alinhar um método para a análise dos resultados obtidos. Nesta pesquisa optou-se pela análise de conteúdo, que segundo Chizzotti (2006) consiste em relacionar a frequência da citação de tema, medindo valor atribuído a um determinado assunto pelo autor. Bardin (2011) permite complementar que a análise de conteúdo busca desvendar o que há por trás das palavras, possibilitando a atribuição de significados e de interpretação das mensagens. Busca-se, assim, analisar um texto e seus conteúdos elucidando-os, promovendo a clareza de temas, categorias e palavras-chave pertencentes aos relatos em análise.

Na próxima seção analisa-se, primeiramente, a frequência de desenvolvimento da ioga pelas professoras com suas turmas. E, na sequência, os desafios para iniciar ou dar continuidade ao trabalho didático-pedagógico com esta manifestação corporal na escola, nas categorias: 1) necessidade de domínio teórico-prático da ioga; 2) domínio didáticopedagógico do conteúdo; 3) estrutura e materiais físicos; 4) necessidade do envolvimento da equipe escolar; 5) realização de planejamento ou o preparo prévio das aulas; 6) desenvolvimento de trabalho contínuo com a turma; 7) presença da ioga como conteúdo programático nos currículos. A organização das categorias seguiu a ordem de incidência de respostas apresentadas pelas participantes.

\section{Resultados e discussão}

A respeito da inserção da ioga na escola e a periodicidade das práticas pedagógicas, as professoras foram perguntadas sobre a frequência com que desenvolviam com as crianças os conhecimentos aprendidos/construídos durante a formação. Todas as professoras participantes, exceto as que exercem funções de gestão (3), colocaram em prática o que foi desenvolvido durante a formação em ioga e educação.

Dentre as respostas, nove professoras desenvolvem a ioga semanalmente com seus alunos. Outras quatro professoras conseguem realizar as práticas duas vezes por semana. Três professoras apontaram a frequência quinzenal. Duas professoras realizam diariamente. Por fim, com uma resposta cada, foram indicadas as frequências do trabalho com ioga de três vezes por semana e ocasionalmente. Diante das análises, observa-se uma correspondência 
satisfatória entre a formação e a atuação docente, sendo que para a maioria das professoras a ioga está presente no planejamento escolar todas as semanas.

Ao analisar as respostas das professoras a respeito dos desafios ainda presentes para a continuidade com o trabalho pedagógico com a ioga com as crianças, foram elaboradas sete categorias: 1) necessidade de domínio teórico-prático da ioga; 2) domínio didáticopedagógico do conteúdo; 3) estrutura e materiais físicos; 4) necessidade do envolvimento da equipe escolar; 5) realização de planejamento ou o preparo prévio das aulas; 6) desenvolvimento de trabalho contínuo com a turma; 7) presença da ioga como conteúdo programático nos currículos. Por se tratar de uma questão aberta, algumas participantes indicaram mais de um motivo. Houve uma participante da pesquisa que não atribuiu resposta à questão.

$\mathrm{Na}$ primeira categoria, "necessidade de domínio teórico-prático da ioga", doze professoras destacam que este é um aspecto a ser investido para gerar mais confiabilidade ao desenvolvimento das ações com as crianças. Pelo fato da ioga ser uma filosofia e prática fundamentada em passos interligados para abordagem total do ser, considera-se a relevância do domínio dos ásanas (posturas), yamas e nyamas (valores éticos e morais), pranayamas (respiração), técnicas de concentração e relaxamento para a prática pedagógica da ioga na escola.

Em uma das falas a professora relata que necessita: "ter maior base teórica para que o programa passe segurança aos receptores e para formular projetos a serem apresentados nas instituições para obter apoio do gestor”. Outra professora relatou em sua fala a necessidade de mais "experiências práticas". Em outra resposta uma professora apontou a necessidade de "apropriarmos as atividades executadas aqui" ao se referir às vivências realizadas na formação, seguida por outras participantes que também apontaram em suas respostas a necessidade de "conhecer mais posturas" e "memorizar e absorver os beneficios das posturas".

As posturas citadas, como explica Feuerstein (1998), correspondem aos ásanas, que são movimentos praticados na ioga que envolvem isometria muscular, alongamento, equilíbrio, alinhamento corporal, respiração controlada, foco na consciência corporal, associação com elementos da natureza e personagens da mitologia hindu.

Pimenta (2012) reflete sobre o papel do conhecimento atribuído à educação escolar. A autora aponta que o conhecimento desenvolvido na escola não pode ser reduzido à transmissão de informações, mas que deve se diferenciar por promover o processo de 
humanização. Ao apontar a necessidade de domínio teórico, é cabível refletir também que os professores devem promover o conhecimento articulando-o e contextualizando-o para se tornarem ativos no processo civilizatório.

Ainda tratando do domínio teórico-prático relacionado à ioga, outras professoras citaram a necessidade de: "aprofundar Yamas e Niyamas"; "mais conhecimento sobre os Yama e Niyama". Com base em Feuerstein (1998) os yamas, as disciplinas externas, são relacionados ao comportamento e denominados como: ahimsa (não-violência contra a natureza, animais, os outros e a si mesmo), satya (verdade, não mentir para os outros, nem para si mesmo), asteya (não roubar; válido para itens materiais, ideias, tempo, saúde etc.), brahmacharya (contenção, celibato e equilíbrio da sexualidade) e aparigraha (não acumulação ou desapego em relação a objetos, pessoas, cargos etc.). Já os nyamas, segundo o autor, são as disciplinas internas, definidas por: saucha (purificação ou limpeza do corpo e dos pensamentos), santosha (prática de contentamento diário e agradecimento por todas as situações), tapas (perseverança e disciplina para o desenvolvimento físico, mental e espiritual), svadhyaya (estudo de si e dos textos relacionados ao yoga) e ishvara-pranidhana (entrega ao caminho espiritual).

Pode-se observar nas respostas das participantes que a busca pelo conhecimento na docência não se encerra em um curso, mas permanece em vistas do aperfeiçoamento da prática e do desenvolvimento da ioga articulada ao processo educativo.

As propostas de formação continuada devem proporcionar aos professores possibilidades de inovação e qualidade para o desenvolvimento do ensino e da aprendizagem. É necessário que essas inovações sejam voltadas para a transformação da realidade, em que se buscam concepções e atitudes que melhorem o processo de aprendizagem (MARTINEZ; CABEZAS; SOLER, 2018). O domínio destes conhecimentos específicos sobre a ioga, apontam as professoras, proporciona qualidade e uso de diferentes estratégias com o trabalho do corpo como um todo. García (2002) defende a necessidade de ouvir a opinião dos professores sobre as formações continuadas ofertadas, a fim de melhorar o sistema de educação e a qualidade dos próprios programas de formação.

Incorporar os aprendizados e trazê-los para a própria vida também foi relatado pelas participantes: "já realizo algumas atividades, mas quero apropriar cada vez mais dos conhecimentos para que realmente esteja fazendo parte da minha vida, ou melhor, que seja a minha própria vida cotidianamente”. Sayão (2002) ressalta a importância do professor fazer a leitura das linguagens infantis e disponibilizar de sua estrutura corporal para compreender este 
universo, sendo participante dele. Para Imbernón (2016) é preciso também considerar que há um período experiencial de apropriação e integração do que o professor desenvolve em relação às suas próprias vivências.

A segunda categoria de análise: “domínio didático-pedagógico do conteúdo”, tal domínio, neste caso, relacionado à manifestação corporal da ioga, foi enfatizada por um grupo de oito professoras como uma necessidade para o desenvolvimento do trabalho na escola. Uma delas mencionou que "gostaria de estar mais segura dos movimentos para passá-los para as crianças". A necessidade da prática pessoal foi citada por diferentes professoras: "para ampliar o trabalho com o Ioga necessito de mais prática pessoal”. Outra participante também coloca que precisa de “mais experiências práticas do conteúdo”. É importante salientar que o programa de formação também assumiu como objetivo aproximar as participantes das práticas da ioga, alcançando resultados não apenas no ensino, mas na esfera pessoal de cada uma, sendo constatado que

Tendo em vista a ênfase dada na prática de Ioga, as educadoras consideram que a proposta foi assertiva ao trazer o foco para a pessoa (o Ser) e não apenas ao papel profissional, exceção nos projetos formativos desenvolvidos pelos sistemas de ensino que centram as formações em modelos de cursos teóricos nos quais o professor/a não é visto/a em sua totalidade. (ROSSI; MIZUNO; CARVALHO, 2017, p. 441)

É preciso ressaltar que a formação, como aponta Charlot (2007), não é reduzida à aprendizagem de práticas, mas emerge da relação entre saberes, práticas e comportamentos relacionados com o sentido que cada professor, no âmbito da sua individualidade, atribui ao seu trabalho, bem como das apropriações geradas por cada profissional.

Em três respostas pode-se verificar o uso dos termos "vivências" e "experiências" como necessidade para ressignificar os conhecimentos em conteúdos escolares. Observa-se a necessidade em conciliar a teoria e a prática, pois não é possível realizar um bom trabalho pautando-se em uma formação continuada unilateral. Charlot (2007) refere-se ao saber da prática como algo consistente, não apenas moldado a uma prática. $\mathrm{O}$ autor aponta que esse saber pode colaborar com uma competência suplementar, mas não está restrito apenas à aplicação, pois é um saber específico, considerando sua propriedade de contextualização e realização de objetivos. Ainda, para Charlot, há saberes que são inscritos no corpo e a sua apropriação passa pela experiência corporal.

Imbernón (2016) ressalta que apesar do reconhecimento da importância de investimentos em formação continuada de professores, ainda há um predomínio da teoria e 
uma descontextualização do que é ofertado nos programas formativos. O autor defende que é preciso descentralizar a preocupação em formar professores que tenham apenas domínio teórico, mas que a inovação seja uma constante a ser desenvolvida pelas propostas formativas. O que ainda prevalece é primeiro formar para a teoria, mas na verdade a própria formação continuada deve estar fundamentada em um caráter inovador. Considerando a inovação como algo que provoque modificações, Harres et al. (2018, p. 04) defende que "É preciso uma formação centrada no desenvolvimento de capacidades que auxiliem na tomada de decisões mais adequadas, qualificando a vida em nível individual e coletivo", reiterando também a centralidade do professor em seu processo de formação.

A terceira categoria, "estrutura e materiais físicos", englobou a fala de seis professoras, que responderam encontrar dificuldades para o trabalho didático com a ioga na escola relacionado às questões estruturais e de materiais, relatando a falta de "colchonetes na escola", de "espaço físico maior" e de "tatames". Diante da realidade de algumas escolas públicas, uma estrutura que ofereça riscos ou que não seja confortável para a acomodação dos alunos pode comprometer a realização das práticas e dos resultados esperados pelas professoras. Contudo, as atividades de ioga podem ser realizadas em diferentes espaços, como por exemplo, um exercício de respiração ou a realização de alguns ásanas na posição sentada, no próprio ambiente em sala de aula.

A "necessidade de envolvimento da equipe escolar", que compôs a quarta categoria de análise, lançou luz para os relatos de três professoras que consideram importante o apoio dos que compõem a esfera escolar para a inserção da ioga no contexto escolar. Quando uma das participantes expressa que necessita "de maior abertura por parte dos professores", observase certa resistência de alguns profissionais em aceitar ou incluir a ioga nas atividades didáticas. Este pensamento é reiterado por mais uma resposta: "no meu caso, [necessito] de professores que abracem a causa". O trabalho coletivo nas escolas revela-se como relevante para promover inovações nas práticas. Martínez, Cabezas e Soler (2018) identificaram que é eminente a necessidade que os professores apresentam de compartilhar e envolver a equipe em que trabalham, com os conhecimentos desenvolvidos, a fim de propor práticas inovadoras na escola.

A quinta categoria é composta pelo apontamento de duas professoras, que relataram a necessidade de "realização de planejamento ou o preparo prévio das aulas". Uma relata que precisa "pensar numa estratégia melhor para adaptá-los ao conteúdo (arte)". No entendimento desta participante, a prática da ioga poderia ser entendida como arte e inserida 
no corpo de conhecimentos desta área, o que remete aos relatos sobre conceber o movimento corporal não como linguagem exclusiva da disciplina de educação física, mas como linguagem da criança que pode estar presente em todas as áreas de conhecimento. A segunda participante diz "precisar adaptar atividades conforme a idade das crianças". A ioga pode ser desenvolvida por pessoas de diferentes faixas etárias, desde que no contexto infantil sua realização se faça por intermédio da brincadeira, com cotação de histórias, músicas, valendose do universo lúdico e da imaginação próprios à infância.

Deutsch et al. (2015) defende que o trabalho de ioga na escola abrange diferentes esferas, como administrativas e pedagógicas, pois o planejamento envolvendo esta prática necessita de definição de conteúdos e estratégias, quantidade de aulas a ser desenvolvidas, verificação dos espaços e a aceitação da proposta pelo coletivo escolar.

O "desenvolvimento de trabalho contínuo com a turma", organizado como sexta categoria, constituiu tema relevante para duas professoras. Uma das professoras destacou que: "espero continuar com os alunos da mesma faixa etária deste ano em 2017. A escola em que trabalho me dá liberdade e recursos para a execução da prática com as crianças”. Esta última expressão demonstra um ambiente inverso ao já relatado dentro de um mesmo sistema de ensino. A formação continuada por si só não consegue almejar resultados se no ambiente escolar o professor não contar com uma gestão democrática, se não for reconhecido enquanto sujeito crítico, detentor do saber docente e participante de uma educação que visa transformar e proporcionar o contato com a cultura humana construída historicamente, neste caso, com a cultural corporal, uma forma de expressão da linguagem infantil. Ressalta-se que a educação na infância deve contemplar diversas linguagens, possibilitar diferentes formas de expressão, concebendo o ser humano como um todo e possibilitando sua participação na própria construção histórica e social (ROSSI, 2013).

Em outra fala, uma professora relata com segurança a prática cotidiana com a ioga em sua turma: "Já trabalho semanalmente atividades com meus alunos e eles já se habituaram, já faz parte da nossa rotina". Pelo relato, a formação tem cumprido com os objetivos da transposição didática, oferecendo aos alunos o contato com uma cultura corporal produzida pela história humana. A prática frequente de ioga na escola pode trazer diversos benefícios às crianças, como calma, respeito aos colegas, aprender a lidar com sentimentos e emoções e trazer bem-estar, como Foletto (2016) descreve.

$\mathrm{Na}$ última categoria de análise, a "presença da ioga como conteúdo programático nos currículos", foram abrangidos os relatos de duas professoras, indicando a necessidade da ioga 
"fazer parte do conteúdo programático". Entende-se como conteúdo programático o detalhamento dos conhecimentos, objetivos, temas e habilidades que serão abordados no planejamento didático-pedagógico, além do reconhecimento da escola/currículo como tal. A Base Nacional Comum Curricular/BNCC (BRASIL, 2017), no âmbito do campo de experiências propostas à educação infantil, garante a centralidade do corpo em práticas pedagógicas que visem desenvolver uma emancipação por meio do envolvimento corporal e sua comunicação e expressão, reconhecendo a emoção e a linguagem como constituintes deste corpo. O documento afirma que a escola deve promover oportunidades significativas de movimento por meio da ludicidade, confirmando assim que a ioga pode ser desenvolvida com as crianças como forma de diversificar o acesso à cultura corporal.

A análise dos relatos das professoras permitem verificar que para implementar mudanças na prática pedagógica, além dos saberes, conhecimentos e práticas veiculados no contexto da formação continuada, cabe investir em um contexto multidimensional após a ação formativa, o qual envolve aprofundar conhecimentos teórico-práticos, da ioga neste caso, além de dominar didático-pedagogicamente o conteúdo específico. A estrutura e materiais físicos também se configuram como elementos necessários para desenvolver as práticas de ioga na escola, bem como é viável o envolvimento da equipe escolar de modo a apoiar a implementação de novas práticas pedagógicas, como a ioga, no contexto educativo. A realização de planejamento de aulas e o desenvolvimento do trabalho contínuo com a turma são fundamentais para um trabalho bem fundamentado e sistematizado. Por fim, consideram as professoras que inserir a ioga como conteúdo programático no currículo pode contribuir para inserir ou consolidar o seu desenvolvimento didático-pedagógico com qualidade na escola. Refletindo sobre estes indícios, recorre-se a Imbernón (2016) que enfatiza que os modelos de formação devem sempre ser centrados nos professores e devem criar condições e proporcionar ambientes de aprendizagem, aproximando-os também de novas perspectivas de ensino e metodologias de aprendizagem, sem desconsiderar a necessária releitura da formação no contexto de prática pedagógica.

\section{Considerações finais}

A presente pesquisa teve como objetivo analisar o desenvolvimento e os fatores que impactam o ensino da ioga na educação infantil e nos anos iniciais do ensino fundamental, de 
acordo com professoras participantes de um programa de formação continuada em ioga e educação.

Os conhecimentos filosóficos e práticas da ioga foram inseridos e desenvolvidos semanalmente pela maioria das professoras em suas turmas, verificando, assim, o empenho das docentes em implementar mudanças em seu fazer pedagógico, ressignificando os conhecimentos e práticas desenvolvidos no programa de formação em práticas escolares.

Sobre as necessidades para ampliar ou aprofundar o trabalho didático com a ioga na escola, a maioria das professoras apontou a necessidade do domínio teórico-prático da ioga, reconhecendo-se assim a importante articulação entre a teoria e a prática. É importante que a formação continuada ofereça estrutura para que os professores consigam reelaborar e ressignificar os conhecimentos aprendidos, adequando-os a sua realidade e necessidade, assim como elucida Pimenta (2012).

Outro apontamento que se destaca foi a necessidade de domínio didático-pedagógico do conteúdo. A ioga é uma prática pouco presente nos currículos de formação de professores. Para que o professor construa seu repertório didático é preciso, também, que a formação do qual participa ofereça instrumentos para gerar o protagonismo docente sobre suas ações de ensino.

Os relatos apontaram que as professoras ainda necessitam de um contexto para além da formação continuada que possibilite o desenvolvimento da ioga na escola, como o envolvimento da equipe escolar e da gestão, assim como uma estrutura que possibilite que os diferentes passos da ioga sejam desenvolvidos com os alunos, de forma motivante e formativa.

A ioga é uma prática e filosofia que consegue de forma satisfatória desenvolver a linguagem corporal e o autoconhecimento, e, por meio das brincadeiras e de forma lúdica, alcançar os estudantes de todas as idades, desde a educação infantil, proporcionando benefícios para todo o grupo, nas dimensões físicas, afetivas e sociais.

É preciso que se reflita sobre ações de formação continuada que valorizem as experiências pessoais, o compartilhamento de práticas, os saberes advindos dos professores, para que a formação não se torne um aglomerado de informações desarticuladas, mas que resulte na construção de um ensino de qualidade que contemple todas as linguagens desenvolvidas na escola. 


\section{REFERÊNCIAS}

AYOUB, Eliana. Reflexões sobre a Educação Física na educação infantil. Revista Paulista de Educação Física, São Paulo, supl.4, p.53-60, 2001. Disponível em:

http://www.revistas.usp.br/rpef/article/view/139594/134898. Acesso em: 5 jun. 2017.

BARDIN, Laurence. Análise de conteúdo. São Paulo: Grupo Almedina, 2011.

BENVINDO, Arianne Santos. A yoga como atividade lúdica na Educação Física escolar. 2015. 21f. Trabalho de conclusão de curso (Licenciatura em Educação Física). Faculdade de Ciências da Educação e Saúde Centro Universitário de Brasília - UniCEUB, Brasília, 2015. Orientador: Prof. Tácio Rodrigues da Silva Santos. Disponível em:

http://repositorio.uniceub.br/bitstream/235/7557/1/21355039.pdf. Acesso em: 8 ago. 2018.

BOGDAN, Robert. C.; BICKLEN, Sari. Knopp. Investigação qualitativa em educação.

Portugal: Porto Editora. 1994.

BRASIL. Ministério da Educação. Base Nacional Comum Curricular - BNCC.

Brasília, DF, 2017. Disponível em: http://basenacionalcomum.mec.gov.br/abase/. Acesso em: 4 abril 2018.

CAETANO, Ana Paula Viana. Pensamento ético dos professores - o lugar da intuição e das emoções. Revista Portuguesa de Pedagogia. Extra série, 2011, p. 125-134. Disponível em: https://www.google.com/url? sa=t\&rct=j\&q=\&esrc=s\&source=web\&cd=1\&cad=rja\&uact=8\& ved=2ahUKEwjd0oOMxNLeAhWLFpAKHT4_A38QFjAAegQICRAC\&url=http\%3A\%2F\% 2Fimpactum-

journals.uc.pt $\% 2$ Frppedagogia\%2Farticle $\% 2 F d o w n l o a d \% 2 F 1310 \% 2 F 758 \% 2 F \& u s g=A O v V a$ w2-2MDMxAKc4v7m-yduNjru. Acesso em: 12 mar. 2018.

CHARLOT, Bernard. Relação com o saber, formação dos professores e globalização: questões para a educação hoje. Porto Alegre: Artmed, 2005.

CHIZZOTTI, Antonio. Pesquisa qualitativa em ciências humanas e sociais. Petrópolis: Vozes, 2006.

DEBORTOLI, José Alfredo. et al. Infância e conhecimento escolar: princípios para a construção de uma educação física "para" e "com" as crianças. Revista Pensar a Prática, n. 5, p. 92-105, 2002. Disponível em: https://www.revistas.ufg.br/fef/article/view/48/45. Acesso em: 3 jun. 2017.

DEUTSCH, Silvia et al. Produção de material didático: estratégias inovadoras para aulas de Yoga. In: XIII CONGRESSO INTERNACIONAL DE TECNOLOGIA NA EDUCAÇÃO. Anais... 2015. Disponível em:

http://intranet.pe.senac.br/dr/ascom/congresso/anais/2015/index.html. Acesso em: 8 mai. 2018.

EHRENBERG, Monica Caldas. A linguagem da cultura corporal sob o olhar de professores da educação infantil. Revista Pro-Posições. v. 25, n. 1 (73), p. 181-198, 2014. Disponível 
em: http://www.scielo.br/scielo.php?pid=S0103-

73072014000100010\&script=sci_abstract\&tlng=pt. Acesso em: 13 dez. 2017.

FARIA, Amanda Cristina, et al. Yoga na escola: por uma proposta integradora em busca do autoconhecimento. In: CONGRESO IBEROAMERICANO DE CIENCIA, TECNOLOGÍA, INNOVACIÓN Y EDUCACIÓN. Anais... Buenos Aires, 2014. Disponível em:

https://www.google.com/url?sa=t\&rct=j\&q=\&esrc=s\&source=web\&cd=1\&ved=2ahUKEwjE 4dmkp8_eAhVEjJAKHc-

iDL8QFjAAegQIBxAC\&url=https\%3A\%2F\%2Fwww.oei.es\%2Fhistorico\%2Fcongreso2014 \%2Fmemoriactei\%2F1519.pdf\&usg=AOvVaw0apQkZDAZYki8g1nciM4zA. Acesso em: 25 jun. 2018.

FEUERSTEIN, Georg. A tradição do Yoga. São Paulo: Pensamento, 1998.

FLAK, Micheline.; COULON, Jacques. Yoga na educação: integrando corpo e mente na sala de aula. Florianópolis: Comunidade do Saber, 2007.

FOLETTO, Julia Ceconi. As percepções de crianças pré-escolares acerca da prática de yoga. 2016. 50f. Trabalho de Conclusão de Curso (Bacharelado em Educação Física). Escola de Educação Física, Fisioterapia e Dança. Universidade Federal do Rio Grande do Sul, Porto Alegre, 2016. Orientadora: Profa. Miriam Stock Palma. Disponível em: https://www.lume.ufrgs.br/handle/10183/156510. Acesso em: 15 set. 2018.

GARANHANI, Marinelma Camargo.; NADOLNY Lorena Fatima. A linguagem movimento na educação de bebês para a formação de professores. Educação e Realidade. Porto Alegre, v. 40, n. 4, p. 1005 - 1026, out./dez. 2015. Disponível em:

https://seer.ufrgs.br/educacaoerealidade/article/view/51737. Acesso em: 10 out. 2018

GARCÍA, Carlos Marcelo. Los professores como trabajadores del conocimiento.

Certidumbres y desafios para una formación a lo largo de la vida. Educar 30, 2002. p. 27-56.

Disponível em: https://www.raco.cat/index.php/Educar/article/viewFile/20762/20602. Acesso em: 16 out. 2018

GIL. Antonio Carlos. Métodos e técnicas de pesquisa social. São Paulo: Atlas, 2006.

HARRES, João Batista Siqueira et al. Constituição e práticas de professores inovadores: um estudo de caso. Ens. Pesqui. Educ. Ciênc. (Belo Horizonte). Belo Horizonte, v. 20, e2679, 2018. Disponível em: <http://www.scielo.br/scielo.php?script=sci_arttext\&pid=S1983$21172018000100201 \& \operatorname{lng}=$ en\&nrm=iso>. Acesso em: 23 out. 2018.

IMBERNÓN, Francisco. Formação permanente do professorado: novas tendências. São Paulo: Cortez, 2009.

IMBERNÓN, Francisco. Qualidade do ensino e formação do professorado: uma mudança necessária. São Paulo: Cortez, 2016.

KISHIMOTO, Tizuko Morchida. LDB e as instituições de Educação Infantil: desafios e perspectivas. Revista Paulista de Educação Física, São Paulo, supl. 4, p. 7-13, 2001. 
Disponível em: http://citrus.uspnet.usp.br/eef/uploads/arquivo/v15\%20supl4\%20artigo1.pdf. Acesso em: 18 ago. 2018.

MACEDO, Elina Elias; NEIRA, Marcos Garcia. A Educação Física na creche: tematizando as práticas corporais. Revista Brasileira de Educação Física e Esporte. São Paulo, 31, jan.mar. 2017, p. 99-106. Disponível em: http://www.revistas.usp.br/rbefe/article/view/141767. Acesso em: 17 mai. 2018.

MARTINS, Florbela Santos; CUNHA, Antonio Camilo. Yoga com crianças: Um caminho pedagógico-didáctico. In: SEMINÁRIO INTERNACIONAL DE EDUCAÇÃO FÍSICA, LAZER E SAÚDE. Anais... Braga: CIED, 2011. p.1-17. Disponível em: http://repositorium.sdum.uminho.pt/handle/1822/22231. Acesso em: 10 out. 2018

MARTINES, Mariana Ferreira. Os benefícios da pratica do yoga natural para crianças de 06 a 10 anos no aspecto da postura física, melhor respiração e concentração. 2009.

64f. Trabalho de conclusão de curso (Licenciatura em Pedagogia). Faculdade de Educação. Universidade Estadual de Campinas, Campinas, 2009. Orientador: Prof. Dr. Rogerio Adolfo de Moura. Disponível em:

http://www.bibliotecadigital.unicamp.br/document/?code=000474716\&opt=1. Acesso em: 25 set. 2018.

MARTÍNEZ, Marcos Jesus Iglesias; CABEZAS, Inés Lozano; SOLER, Irene Roldan. La calidad e innovación educativa en la formación continua docente: un estudio cualitativo en dos centros educativos. Revista Iberoamericana de Educación, vol. 77, n. 1, 2018. p. 13-34. Disponível em: https://rieoei.org/RIE/article/view/3090. Acesso em: 20 jul. 2018.

MASSOLA, Maria Ester Azevedo. Vamos praticar yoga? Yoga para crianças, pais e professores. São Paulo: Phorte, 2008.

MINAYO, Maria Cecilia Souza (Org.). Trabalho de campo: contexto de observação, interação e descoberta. In: 1993. p. 61-77.

Pesquisa social: teoria, método e criatividade. Petrópolis: Vozes,

OLIVEIRA, Vinicius Machado; SOUZA, Juliano. A infância, o brincar e o jogar: reflexões a partir do referencial teórico de Norbert Elias. Educação em Revista. Belo Horizonte, n. 34, e186748, 2018. Disponível em:

http://www.scielo.br/scielo.php?script=sci_abstract\&pid=S010246982018000100139\&lng=pt\&nrm=iso\&tlng=pt. Acesso em: 10 set. 2018.

PIMENTA, Selma Garrido (Org.). Professor reflexivo: construindo uma crítica. In: GHEDIN, Evandro (Orgs.). Professor Reflexivo no Brasil gênese e crítica de um conceito. São Paulo: Cortez, 2012.

POSSIGNOLO, Lígia Oliveira. Yoga na Escola. 2012. 86f. Trabalho de conclusão de curso (Licenciatura em Pedagogia). Faculdade de Educação. Universidade Estadual de Campinas, Campinas, 2012. Orientador: Prof. Dr. Adilson Nascimento de Jesus. Disponível em: file:///C:/Users/guilh/AppData/Local/Temp/PossignoloLígiaOliveira_TCC-1.pdf. Acesso em: 10 mar. 2018. 
ROSSI, Fernanda; MIZUNO, Julio; CARVALHO, Maria Lúcia Nejm de. Projeto de extensão "Corporeidade e Ioga na Escola": formação integral para professoras, futuros professores e crianças da educação infantil. In.: OLIVEIRA NETO, Luttgardes et al. (Orgs.). Extensão universitária: diversidade e desenvolvimento humano. São Paulo: Cultura Acadêmica, 2017, p. 429-444.

ROSSI, Fernanda. Implicações da formação continuada na prática pedagógica do(a) professor(a) no âmbito da cultura corporal do movimento. 286f. Tese (Doutorado em Ciências da Motricidade). Instituto de Biociências, Universidade Estadual Paulista, Rio Claro, 2013. Orientadora: Profa. Dra. Dagmar Ap. Cynthia França Hunger. Disponível em: https://repositorio.unesp.br/handle/11449/100445. Acesso em: 10 fev. 2017.

SAYÃO, Deborah Tomé. Corpo e movimento: notas para problematizar algumas questões relacionadas à educação infantil e à Educação Física. Revista Brasileira de Ciências do Esporte, Campinas, v. 23, n. 2, p. 55-67, jan. 2002. Disponível em: http://revista.cbce.org.br/index.php/RBCE/article/view/270. Acesso em: 15 jun. 2017.

SILVEIRA, Maria Claurenia Andrade. Yoga para crianças: uma prática em construção. Revista Religare, v.9, n.2, p. 177-185, 2012. Disponível em: http://www.periodicos.ufpb.br/ojs/index.php/religare/article/view/15875. Acesso em: 17 mai. 2017.

\section{$\underline{\text { SOBRE AS AUTORAS }}$}

\section{Fernanda Pastori Franzé}

Mestranda em Ciências da Motricidade, pela Universidade Estadual Paulista (UNESP)campus de Bauru, Brasil. Professora de Educação Infantil no Sistema Municipal de Ensino de Bauru. Membro do Grupo de Estudos e Pesquisas Históricas, Sociológicas e Pedagógicas em Educação Física - CNPq. E-mail: pastorifernanda@gmail.com

(iD) http://orcid.org/0000-0002-4174-1687

\section{Fernanda Rossi}

Doutora em Ciências da Motricidade, pela Universidade Estadual Paulista (UNESP), campus de Rio Claro, Brasil. Professora Assistente Doutora na UNESP Bauru, Faculdade de Ciências, Departamento de Educação. Docente credenciada no Programa de Pós-Graduação em Ciências da Motricidade - UNESP Interunidades e no Programa de Pós-Graduação em Docência para a Educação Básica - Mestrado Profissional - UNESP Bauru. Vice-líder do Grupo de Estudos e Pesquisas Históricas, Sociológicas e Pedagógicas em Educação Física CNPq. E-mail: fernanda.rossi@unesp.br

\section{http://orcid.org/0000-0002-4760-4712}

